\title{
(อ) OPEN ACCESS \\ Can TEN4 distinguish bruises from abuse, inherited bleeding disorders or accidents?
}

\author{
Alison Mary Kemp 지 ,' Sabine Ann Maguire (1) , ${ }^{1}$ Dianne E Nuttall, ${ }^{1}$ Peter Collins, ${ }^{2}$ \\ Frank D Dunstan, ${ }^{1}$ Daniel Farewell ${ }^{1}$
}

- Additional material is published online only. To view please visit the journal online (http://dx.doi.org/10.1136/ archdischild-2020-320491).

${ }^{1}$ Division of Population Medicine, Cardiff University School of Medicine, Cardiff, UK ${ }^{2}$ Haematology, Cardiff and Vale UHB, Cardiff, UK

\section{Correspondence to} Professor Alison Mary Kemp Division of Population Medicine, Cardiff University School of Medicine, Cardiff CF14 4YS, UK; kempam@cardiff.ac.uk

Received 18 August 2020 Revised 26 November 2020 Accepted 1 December 2020 Published Online First 18 February 2021

\section{Check for updates}

(C) Author(s) (or their employer(s)) 2021. Re-use permitted under CC BY. Published by BMJ.

To cite: Kemp AM

Maguire SA, Nuttall DE, et al. Arch Dis Child

2021:106:774-779.

\section{ABSTRACT}

Objective Does TEN4 categorisation of bruises to the torso, ear or neck or any bruise in $<4$-month-old children differentiate between abuse, accidents or inherited bleeding disorders (IBDs)?

Design Prospective comparative longitudinal study. Setting Community.

Patients Children $<6$ years old.

Interventions The number and location of bruises compared for 2568 data collections from 328 children in the community, 1301 from 106 children with IBD and 342 abuse cases.

Main outcome measures Likelihood ratios (LRs) for the number of bruises within the TEN and non-TEN locations for pre-mobile and mobile children: abuse vs accidental injury, IBD vs accident, abuse vs IBD.

Results Any bruise in a pre-mobile child was more likely to be from abuse/IBD than accident. The more bruises a pre-mobile child had, the higher the LR for abuse/IBD vs accident. A single bruise in a TEN location in mobile children was not supportive of abuse/IBD. For mobile children with more than one bruise, including at least one in TEN locations, the LR favouring abuse/IBD increased. Applying TEN4 to collections from abused and accidental group $<48$ months of age with at least one bruise gave estimated sensitivity of $69 \%$ and specificity for abuse of $74 \%$.

Conclusions These data support further child protection investigations of a positive TEN4 screen in any pre-mobile children with a bruise and in mobile children with more than one bruise. TEN4 did not discriminate between IBD and abuse, thus IBD needs to be excluded in these children. Estimated sensitivity and specificity of TEN4 was appreciably lower than previously reported.

\section{INTRODUCTION}

In young children who present with concerning patterns of bruising, the differential diagnosis includes accidental injury, ${ }^{1}$ physical abuse and coagulation disorders such as inherited bleeding disorders (IBDs). The clinician must identify the cause of the bruising and decide whether the child requires further clinical or child protection investigations.

In 2010, Pierce et al published a pilot study "discriminating bruising characteristics, to model those findings into a decision tool for screening children at high risk for abuse". ${ }^{2}$ The Bruise Clinical Decision Rule (BCDR) was developed from 71 children (42 had been abused) admitted to paediatric intensive care units with trauma and examined for bruising. The TEN4 BCDR emerged whereby "bruising on the torso, ear, or neck for a child

\section{What is already known on this topic?}

$\Rightarrow$ Bruising is the most common presentation of accidents, physical abuse and inherited bleeding disorder in young children, and clinicians must differentiate between these three conditions.

$\Rightarrow$ The TEN4 bruising clinical decision rule (sensitivity $97 \%$, specificity $84 \%$ for abuse in paediatric intensive care unit) is being used in wider clinical settings.

$\Rightarrow$ It is important to test the rule in these wider settings.

\section{What this study adds?}

$\Rightarrow$ These data support further child protection investigations of a positive TEN4 screen in a pre-mobile child and a mobile child with more than one bruise.

$\Rightarrow$ TEN4 did not discriminate between inherited bleeding disorder (IBD) and abuse, thus IBD must be excluded in these children.

$\Rightarrow$ Estimated sensitivity (68.8\%) of TEN4 and specificity $(72.1 \%)$ for abuse was appreciably lower in this study than previously reported.

$<48$ months of age and bruising in any region for an infant $<4$ months of age, in the absence of a publicly witnessed injury" had a sensitivity of $97 \%$ and a specificity of $84 \%$ for predicting abuse. TEN4 is gaining momentum internationally as a recommended decision rule across a wider population of children. ${ }^{3}$

We previously described the pattern of bruising in three groups of children: those with suspected abuse, bruises from day-to-day activities and accidents, and children with IBD. ${ }^{145}$ This study uses the datasets from these three publications to determine whether the categorisation of bruising used in the TEN4 BCDR can differentiate between these three conditions.

\section{METHODS}

Children (0-6 years old) were recruited from three sources between 2003 and 2011. Three different cohorts were recruited, abuse cases:

- Physical abuse: The medical records of children referred to two paediatric child protection teams in southeast Wales for assessment. ${ }^{4}$ 
- Accidents: children from well-baby clinics, hospital outpatient clinics, and mother and baby groups in south Wales. ${ }^{1}$

- IBD: children attending six haemophilia centres across UK and Canada. ${ }^{5}$

\section{Definitions}

Physical abuse was confirmed at multiagency child protection strategy meetings or case conference, where a joint decision as to probable abuse was made based on all information available. IBDs included haemophilia A, factor XI deficiency, von Willebrand disease or platelet disorders. Children with mild and moderate IBD were not analysed separately due to insufficient numbers of subjects. The accidental group included children from the community who sustained bruises from accidents or everyday activities.

\section{DATA COLLECTION}

Parents of the 'accidental group' and those with IBD prospectively recorded the number of bruises, and their location, on a body map weekly, together with the child's developmental stage for up to 12 weeks. The accuracy and consistency of data recording was externally validated in a random selection of cases by the research nurse. ${ }^{1}$ The same data were recorded on a standardised proforma when the abuse group were assessed by the medical child protection team. Full details of how bruises were recorded are available in previous publications. ${ }^{145}$

Bruising from immunisations or venepuncture and children with any clinical or social concerns for child maltreatment in the accidental and IBD group were excluded. Bruises on the shins, often deemed a universal finding among ambulatory children, were not consistently recorded by clinicians during child protection assessments and were excluded from each group.

Bruises were grouped into 18 locations ${ }^{14}$ (figure 1). Children were categorised into two developmental groups: pre-mobile (non-rolling, rolling over and sitting) and mobile (crawling, bottom shuffling, cruising or walking).

\section{ANALYSIS}

Comparative analyses were performed to determine whether the extent of bruising in the TEN locations had the potential to discriminate between bruises from abuse, IBD and accidents for pre-mobile and mobile children. The analysis was predicated on previous findings that both the distribution of bruises and the total number of bruises varied between the three groups of children. Bruises recorded at each data collection were categorised according to the number in each of the TEN locations Torso (chest, abdomen, back, buttocks, genitourinary), Ears or Neck or in the non-TEN locations (head, face, arms, upper legs, hands, feet).

Multilevel Poisson regression was used to analyse the number of bruises in TEN4 and non-TEN4 locations, quantifying how the average number of bruises in the two locations varied with study group and with the child's developmental group. Using the statistical software R, generalised linear mixed models with a log link function were fitted. Interactions between study group and developmental group, and between study group and bruise location were allowed for, additionally including a random effect for each child's general tendency to bruise (online supplemental appendix 1).

In our primary analysis of likelihood ratios (LRs), we used a standard approach for modelling correlated longitudinal data and included a random effect that allows for each child to have a different tendency to bruise. LRs were used to summarise the
Table 1 Number of children, their gender and the number of data collections within the accidental, inherited bleeding disorders and abuse groups according to their independent mobility

\begin{tabular}{lllll}
\hline & Accidental & $\begin{array}{l}\text { Inherited } \\
\text { bleeding } \\
\text { disorder }\end{array}$ & Abused & Total \\
\hline No of children & 328 & 106 & 346 & 780 \\
\hline Male & 145 & 81 & 208 & 434 \\
\hline Female & 168 & 15 & 138 & 321 \\
\hline Unknown & 15 & 10 & 0 & 25 \\
\hline No of collections & 2568 & 1301 & 346 & 4211 \\
\hline Pre-mobile & 932 & 136 & 107 & 1175 \\
\hline Mobile & 1636 & 1165 & 239 & 3036 \\
\hline $\begin{array}{l}\text { No of collections per child } \\
\text { (median and range) }\end{array}$ & $8(1-24)$ & $12(1-36)$ & 1 & \\
\hline
\end{tabular}

results of each model fit. A LR of $\geq 10$ was considered strongly predictive, while a LR between 1 and 10 supported a small difference.

To determine whether using an age cut-off (as in TEN4) rather than pre-mobile versus mobile made any difference to the discriminatory power, the analysis was repeated for those $<4$ months old and those older.

To make a comparison with the original sensitivities and specificities for abuse quoted by Pierce $e$ t al, the TEN4 BCDR ${ }^{26}$ was applied to the collections in the abused group and the accidental group where at least one bruise was recorded for the whole study group and for those $<48$ months of age.

\section{RESULTS}

In total, 780 children provided 4211 data collections (table 1); 1175 collections in pre-mobile children, median age 5 months (IQR 3-6 months), and 3036 collections in mobile children, median age 26 months (IQR 13-42 months).

\section{Frequency of bruises}

Pre-mobile children in the accidental and IBD group rarely bruised, but once mobile they had frequent bruises (figure 2). By contrast, the abused pre-mobile children often had multiple bruises. The IBD and abused children showed the largest number of bruises overall. There was a wider variation between the number of bruises recorded at different time points on the same child for the IBD (range 0 to $>40$ ) than for accidental groups (range $0-10$ bruises) per collection.

\section{Distribution of bruises}

Bruises to the torso were recorded in the pre-mobile IBD and abuse groups (figure 1). The IBD pre-mobile infants had more bruises on the upper arms, whereas the abuse group had more bruises to the cheeks, eyes and neck.

In the mobile group, bruises were commonly seen in the facial-T (forehead, nose, upper lip, chin) ${ }^{7}$ across all three groups. The distribution of bruises in the mobile abused and IBD children were similar with bruises to the torso. However, the prevalence of bruises to the cheeks, neck, ears and eyes was greater among the abused children than those with IBD. The latter had more bruises to the lower arms.

\section{Model fit}

Relative to the accidental group, both IBD and abuse groups exhibited significantly more bruising in TEN and non-TEN locations. Pre-mobile infants had significantly fewer bruises than mobile children, though this difference was much smaller in the 


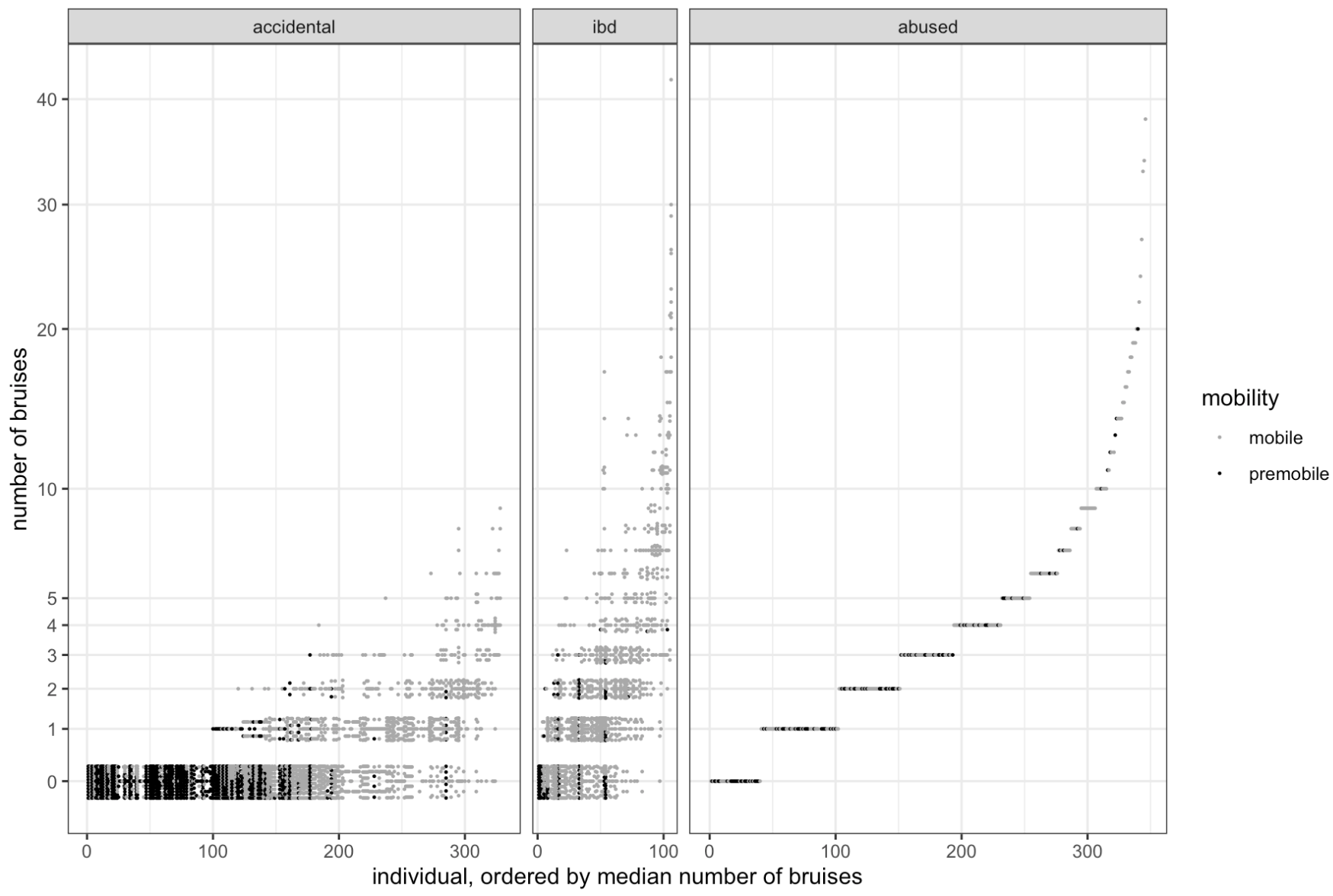

Figure 2 Bruise count at each of 4211 data collections for 780 children from three groups of children: accidental (minor accidents and everyday activities), abused and inherited bleeding disorder. Data are ordered by the median number of bruises per child from children with the least to those with the greatest bruise frequency.

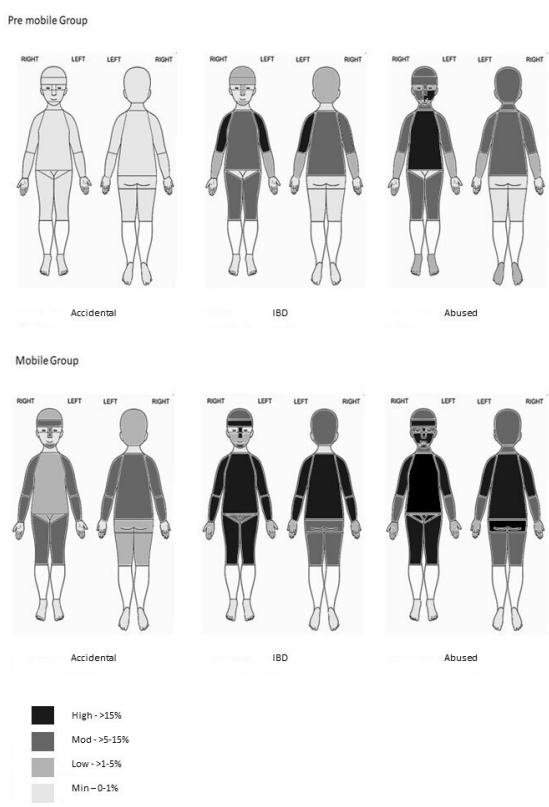

Figure 1 Distribution of bruises across 18 sites $^{1}$ on the body among the accidental, abuse and inherited bleeding disorder groups (IBD), across two developmental stages (pre-mobile, mobile). The figure shows the proportion of collections in which there was at least one bruise at the location indicated (minimal, $0 \%-1 \%$; low, $1 \%-5 \%$; moderate, $5 \%-15 \%$; high, $>15 \%$ ).
IBD and abuse groups. In all groups, there were fewer bruises in TEN locations than in non-TEN locations, but this difference was less pronounced among the IBD and abuse groups.

There was between-child variation in the amount of bruising (SD 0.87). This captures the idea that some children exhibit more bruises than others. An extreme child in the accidental group (at the 97.5th percentile in terms of their tendency to bruise) exhibits roughly the same average number of bruises as the median child in the abuse group (figure 2).

\section{Likelihood ratios}

A pre-mobile child with a single bruise was more likely to have been abused or have IBD than to be accidentally injured. The more bruises that a child had, the higher the likelihood of abuse/ IBD versus accident. Once a child had two or more bruises, the LRs significantly favoured abuse over IBD. The presence of bruises in the TEN locations was more indicative of abuse than IBD (table 2). Using an age cut-off of 4 months, the LRs showed a similar result. While the LRs using the age cut-off were lower than using the mobility categorisation, the differences did not reach statistical significance. (online supplemental appendix 2)

An isolated bruise in a TEN location in a mobile child was not supportive of abuse or IBD. For mobile children with more than one bruise, at least one of which was in a TEN location, the LRs favouring abuse or IBD over accidents increased (table 3). Using an age cut-off of 4 months instead of our mobile categorisation, the overall trend was the same. However, for children older than 
Table 2 Likelihood ratios (to 2 significant digits) for the number of bruises within the TEN (torso, ears and neck) locations for pre-mobile children: abuse vs accidental injury, inherited bleeding disorders (IBD) vs accidental injury, abuse vs IBD

\begin{tabular}{|c|c|c|c|c|}
\hline $\begin{array}{l}\text { Number of bruises in TEN } \\
\text { sites }\end{array}$ & $\begin{array}{l}\text { Number of bruises } \\
\text { elsewhere }\end{array}$ & Abused vs accidental estimated LR ( $95 \% \mathrm{Cl}$ & IBD vs accidental estimated LR $(95 \% \mathrm{Cl})$ & Abused vs IBD estimated LR $(95 \% \mathrm{Cl})$ \\
\hline 0 & 0 & 0.17 (0.11 to 0.24$)$ & 0.51 (0.38 to 0.63 ) & 0.34 (0.21 to 0.53 ) \\
\hline 0 & 1 & $4.9(3.2$ to 6.9$)$ & 6.8 (4.6 to 9.1$)$ & $0.72(0.55$ to 0.89$)$ \\
\hline 0 & $2+$ & 208 (104 to 376$)$ & 109 (40 to 240$)$ & $1.9(1.2$ to 3.2$)$ \\
\hline 1 & 0 & $11(7.3$ to 16$)$ & $8.8(5.7$ to 12$)$ & $1.3(1.0$ to 1.6$)$ \\
\hline 1 & 1 & 313 (152 to 544$)$ & 118 (45 to 228$)$ & 2.7 (1.8 to 4.1$)$ \\
\hline 1 & $2+$ & 1300 (4080 to 33600$)$ & $1890(407$ to 6110$)$ & 7.1 (2.7 to 18$)$ \\
\hline $2+$ & 0 & 890 (444 to 1660$)$ & 160 (57 to 362$)$ & $5.6(3.2$ to 9.1$)$ \\
\hline $2+$ & 1 & 25000 (7900 to 59000$)$ & 2100 (454 to 7100$)$ & 11.7 (4.7 to 27$)$ \\
\hline $2+$ & $2+$ & 1100000 (210000 to 3600000$)$ & 34000 (4200 to 180000$)$ & 31 (7.2 to 130$)$ \\
\hline
\end{tabular}

4 months of age, the LRs for abuse/IBD against accidental injuries were greater, and thus the power to discriminate improved slightly (online supplemental appendix 2).

Applying the TEN4 BCDR to this dataset for the collections in 300 abused children and 760 collections among the accidental group where the child had at least one bruise, the estimated sensitivity for abuse was $69 \%$ (95\% CI 63\% to 74\%) and specificity was $72 \%$ (95\% CI $69 \%$ to $75 \%$ ). When a developmental cutoff was applied, these values were $73 \%$ (95\% CI 67\% to $77 \%$ ) and specificity fell to $69 \%$ (95\% CI 66\% to 72\%), respectively. To mitigate the effect that collections made on the same child may not be independent, the calculations were repeated but only applied to the first collection in the accidental group that had any bruising; the estimated sensitivity was unaffected and the estimated specificity fell to $65 \%$. To make a more direct comparison with the original TEN4 derivation study, ${ }^{2}$ we applied the TEN4 rule to children less than 48 months of age: the estimated sensitivity remained the same at $69 \%$ and the estimated specificity was 74\% (when applied to the first collection in the accidental group, the estimated specificity fell to $63 \%$ ).

\section{DISCUSSION}

Any bruise in a pre-mobile child was strongly predictive of abuse/IBD and bruising in the TEN locations favoured abuse/ IBD in mobile children who had more than one bruise recorded. When multiple bruises were recorded in the TEN locations, the likelihood of abuse over IBD increased. However, the poor discrimination between abuse and IBD reiterates the need for a haematological investigation in a child with concerning bruising.

The strong association between any bruise in a pre-mobile child and abuse is well established. Such infants rarely sustain accidental bruises. ${ }^{8}$ A recent study ${ }^{9}$ of the causes of bruising in pre-mobile infants highlighted that 54\% (26/46) of those with unexplained bruises were found to have been abused. On further investigation, 43\% (27/63) of infants with initially 'explained' bruises were recognised as being abused. It is notable that $38 \%$ of the abused infants only had a single bruise.

It was unsurprising that the TEN4 bruise categorisation could not discriminate between abuse and IBD, as it was not designed to do so. Widespread bruises occur in both conditions. It was notable, however, that when there were more bruises in the TEN locations, the association with abuse was stronger than with IBD. Jackson et al have previously highlighted the overlap between IBD and suspected abuse, whereby 15\% (29/189) of children with IBD had initially presented with bruising concerning for abuse, $79 \%(23 / 29)$ of whom were younger than 5 years. ${ }^{10}$ Investigations of any child with bruising must include a screen for IBD. It must also be remembered that both conditions can co-exist. ${ }^{11}$

In this dataset, a mobile child (or one older than 4 months) with a single bruise in a TEN location only was more likely to be found in the accidental than the abuse group and the TEN bruise distribution had no power to discriminate either abuse or IBD from accidental injury in these children.

The TEN4 categorisation worked equally well using a developmental cut-off of pre-mobility or an age cut-off of $<4$-month-olds. While the use of an age cut-off is attractive in an emergency department setting, we have always focused on mobility, as bruising frequency and distribution are related to the level of motor development ${ }^{145}$ as 'those who don't cruise, rarely bruise'. ${ }^{12}$

As with any clinical tool, the BCDR is not designed as a diagnostic tool but as a prompt for clinicians when deciding whether to investigate a child further. When a child presents

Table 3 Likelihood ratios (LRs) (to 2 significant digits) for the number of bruises within the TEN locations for mobile children: abuse vs accidental injury, inherited bleeding disorders (IBD) vs accidental injury, abuse vs IBD

\begin{tabular}{|c|c|c|c|c|}
\hline $\begin{array}{l}\text { Number of TEN } \\
\text { bruises }\end{array}$ & $\begin{array}{l}\text { Number of bruises } \\
\text { elsewhere }\end{array}$ & Abused vs accidental estimated LR $(95 \% \mathrm{Cl})$ & IBD vs accidental estimated LR $(95 \% \mathrm{Cl})$ & Abused vs IBD estimated LR $(95 \% \mathrm{Cl})$ \\
\hline 0 & 0 & $0.04(0.02$ to 0.06$)$ & 0.26 (0.19 to 0.34$)$ & 0.16 (0.09 to 0.28$)$ \\
\hline 0 & 1 & $0.22(0.14$ to 0.30$)$ & 0.83 (0.71 to 0.95$)$ & $0.26(0.17$ to 0.38$)$ \\
\hline 0 & $2+$ & $2.62(2.0$ to 3.3$)$ & $3.9(3.0$ to 4.9$)$ & $0.68(0.56$ to 0.76$)$ \\
\hline 1 & 0 & 0.50 (0.31 to 0.71$)$ & $1.1(0.87$ to 1.3$)$ & 0.47 (0.29 to 0.66$)$ \\
\hline 1 & 1 & 2.6 (1.9 to 3.5$)$ & $3.4(2.8$ to 4.2$)$ & $0.78(0.56$ to 0.93$)$ \\
\hline 1 & $2+$ & 31 (24 to 44$)$ & 16 (11 to 25$)$ & $2.0(1.5$ to 2.6$)$ \\
\hline $2+$ & 0 & 9.5 (6.2 to 14$)$ & 4.9 (3.8 to 6.6$)$ & $1.9(1.5$ to 2.4$)$ \\
\hline $2+$ & 1 & 50 (36 to 71$)$ & 16 (11 to 25$)$ & $3.2(2.5$ to 4.1$)$ \\
\hline $2+$ & $2+$ & 600 (360 to 1100$)$ & $73(42$ to 150$)$ & 8.2 (4.9 to 13$)$ \\
\hline
\end{tabular}


for assessment of bruising, a diagnosis of abuse cannot be made from the pattern of bruising alone. These data show that the numbers of bruises have relevance as do other clinical diagnoses. The comprehensive assessment of these children must take account of the explanation for bruising in the context of wider scientific evidence, much of which has been described in systematic reviews ${ }^{1314}$ and in more recent publications. Hibberd et al explored eight causal mechanisms of accidental bruising in children attending the emergency department and showed that, with the exception of falls downstairs or sports injuries, the majority of reported incidents involved a single bruise, and there were sites such as genitalia, ears or neck that were rarely affected. Accidental bruises from a single incident rarely are multiple, occur in clusters or are seen in pre-mobile babies. ${ }^{15} 16$

TEN4 is easy to memorise and simple to use. However, it was derived from a small population with significant trauma warranting admission to PICU but subsequently tested and modified in the emergency department. ${ }^{16}{ }^{17}$ As it is now widely applied in practice, across multiple clinical settings, it was pertinent to explore its potential in a community sample, and those with IBD.

When the TEN4 BCDR itself was applied to the collections from abused and accidentally injured children where at least one bruise was recorded, estimated sensitivity and specificity for abuse were both lower than when calculated by the Pierce group. ${ }^{216}{ }^{17}$ This is likely to be due to the different population used for the accidental group, where the children sustained their bruises from everyday activities and minor injuries. There was no statistically significant difference between these estimations when applied to children $<48$ months of age (as included in the original derivation study for TEN4) or to the extended age range of this study suggesting that TEN4 may be equally applicable to children up to 6 years of age. ${ }^{2}$

The strength of this study is its size, in terms of the number of data collections, and datasets representative of children from all three groups. While the difference in location of bruising between abused and non-abused children of different ages has long been recognised, ${ }^{18}$ TEN4 is the only algorithm that we are aware of to be applied to a combination of alerting sites and age in clinical practice. The security of diagnosis relied on the assessment of the likelihood of abuse at multidisciplinary assessment based on all available information including any bruising that the child had; however, it is extremely unlikely that this would have included the items of interest namely the precise number or location of bruises within or outside of the combined TEN4 regions. Circular reasoning was further mitigated as the data were collected prior to the TEN4 rule publication. However, limitations include the fact that we used repeated recording of bruises from children over time for IBD and accidental cases and there are issues to consider regarding individual child factors. The age range of children included is broader than that studied by Pierce $e t a l^{2}$; however, the majority were $<4$ years old. The IBD cases have been combined within this analysis including all severities, diagnoses and treatment regimens but replicates the situation when children of any severity or any stage in their treatment regimen may present with bruising.

\section{CONCLUSION}

A simple, accurate and easy-to-apply BCDR to identify children at risk of abuse has the potential to save lives. TEN4, developed and validated in a hospital setting, is now being used in a wider population, including primary care and non-trauma settings. ${ }^{3}$ Therefore, it is vital that it is tested among these populations.
This study has reiterated that any bruise in a pre-mobile child, or in the TEN locations in a mobile child with more than one bruise, should prompt investigations. It does not automatically imply the child has been abused. TEN4 did not discriminate those with an IBD from abuse, and screening for IBD must always be considered.

\section{Twitter Alison Mary Kemp @N/A}

Acknowledgements The authors thank all the families who contributed data and Ana Guerrero, Amy Jungmann and Cindy Wakefield.

Collaborators not applicable.

Contributors AMK/DF designed the study and wrote the manuscript. DF analysed and interpreted data and revised the manuscript, had full access to all of the data in the study, and takes responsibility for the integrity of the data and the accuracy of the data analysis. FDD undertook the statistical analysis in the previous studies on which these datasets were derived and edited and approved the manuscript. SAM designed the study, interpreted data and revised the manuscript. PC coordinated the collection of haematology data and participated in study design and manuscript editing and approval. DEN collected the data and coordinated the study governance and produced manuscript illustrations.

Funding The study was funded by the Medical Research Council UK reference G0601638 and received support from the UK Clinical Research Network and National Institute for Social Care and Health and Care Research Wales.

Competing interests None declared.

Patient consent for publication Not required.

Ethics approval Southampton Ethics Committee (05/MRE11/8) (14 January 2005 and amended in October 2007) and IRB of Hospital for Sick Children Toronto (1000013885).

Provenance and peer review Not commissioned; externally peer reviewed.

Data availability statement Data are available on reasonable request. Data are available for up to 15 years following data collection according to university policy and can be made available on reasonable request.

Supplemental material This content has been supplied by the author(s). It has not been vetted by BMJ Publishing Group Limited (BMJ) and may not have been peer-reviewed. Any opinions or recommendations discussed are solely those of the author(s) and are not endorsed by BMJ. BMJ disclaims all liability and responsibility arising from any reliance placed on the content. Where the content includes any translated material, BMJ does not warrant the accuracy and reliability of the translations (including but not limited to local regulations, clinical guidelines, terminology, drug names and drug dosages), and is not responsible for any error and/or omissions arising from translation and adaptation or otherwise.

Open access This is an open access article distributed in accordance with the Creative Commons Attribution 4.0 Unported (CC BY 4.0) license, which permits others to copy, redistribute, remix, transform and build upon this work for any purpose, provided the original work is properly cited, a link to the licence is given, and indication of whether changes were made. See: https://creativecommons.org/ licenses/by/4.0/.

\section{ORCID iDs}

Alison Mary Kemp http://orcid.org/0000-0002-1359-7948

Sabine Ann Maguire http://orcid.org/0000-0001-9870-0547

\section{REFERENCES}

1 Kemp AM, Dunstan F, Nuttall D, et al. Patterns of bruising in preschool children-a longitudinal study. Arch Dis Child 2015;100:426-31.

2 Pierce MC, Kaczor K, Aldridge $\mathrm{S}$, et al. Bruising characteristics discriminating physical child abuse from accidental trauma. Pediatrics 2010;125:67-74.

3 Face it. A movement to end child abuse. Ten-4 bruising rule, 2020. Available: ttps:// faceitabuse.org/ten4rule/

4 Kemp AM, Maguire SA, Nuttall D, et al. Bruising in children who are assessed for suspected physical abuse. Arch Dis Child 2014;99:108-13.

5 Collins PW, Hamilton M, Dunstan FD, et al. Patterns of bruising in preschool children with inherited bleeding disorders: a longitudinal study. Arch Dis Child 2017:102:1110-7.

6 Pierce MC KK, Lorenz DJ, Makoroff K, et al. Bruising clinical decision rule (BCDR) discriminates physical child abuse from accidental trauma in young children 2017.

7 Chang L-T, Tsai M-C. Craniofacial injuries from slip, trip, and fall accidents of children. J Trauma 2007;63:70-4

8 Carpenter RF. The prevalence and distribution of bruising in babies. Arch Dis Child 1999;80:363-6. 
9 Feldman KW, Tayama TM, Strickler LE, et al. A prospective study of the causes of Bruises in Premobile infants. Pediatr Emerg Care 2020;36:e43-9.

10 Jackson J, Miller M, Moffatt M, et al. Bruising in children: practice patterns of pediatric hematologists and child abuse pediatricians. Clin Pediatr 2015;54:563-9.

$11 \mathrm{O}^{\prime}$ Hare AE, Eden OB. Bleeding disorders and non-accidental injury. Arch Dis Child 1984;59:860-4.

12 Sugar NF, Taylor JA, Feldman KW. Bruises in infants and toddlers: those who don't cruise rarely bruise. Puget Sound Pediatric Research Network. Arch Pediatr Adolesc Med 1999;153:399-403.

13 Maguire S, Mann MK, Sibert J, et al. Can you age bruises accurately in children? A systematic review. Arch Dis Child 2005;90:187-9.
14 Royal College of Paediatrics and Child Health. Child Protection Evidence-bruising, 2020. Available: https://www.rcpch.ac.uk/resources/child-protection-evidencebruising

15 Hibberd $\mathrm{O}$, Nuttall D, Watson RE, et al. Childhood bruising distribution observed from eight mechanisms of unintentional injury. Arch Dis Child 2017;102:1103-9.

16 Pierce MC. Bruising characteristics from unintentional injuries in children: the 'green flag' study. Arch Dis Child 2017;102:1097-8.

17 Kaczor KPM, Lorenz D, Makoroff K, et al. An analysis of the impact of age threshold on the performance of a bruising clinical decision rule (BCDR) for discriminating physical abuse from accidental trauma in infants 0-12 months of age. 2017.

18 Roberton DM, Barbor P, Hull D. Unusual injury? Recent injury in normal children and children with suspected non-accidental injury. Br Med J 1982;285:1399-401. 